\title{
The Role of Aryl Hydrocarbon Receptor and Crosstalk with Estrogen Receptor in Response of Breast Cancer Cells to the Novel Antitumor Agents Benzothiazoles and Aminoflavone
}

\author{
Mariana A. Callero and Andrea I. Loaiza-Pérez \\ Research Area, Institute of Oncology “Ángel H. Roffo", University of Buenos Aires, Avenue San Martín 5481, \\ C1417DTB Ciudad de Buenos Aires, Argentina \\ Correspondence should be addressed to Andrea I. Loaiza-Pérez, loaizaa2003@yahoo.com
}

Received 30 April 2011; Accepted 14 June 2011

Academic Editor: Alejandro J. Urtreger

Copyright (๑) 2011 M. A. Callero and A. I. Loaiza-Pérez. This is an open access article distributed under the Creative Commons Attribution License, which permits unrestricted use, distribution, and reproduction in any medium, provided the original work is properly cited.

\begin{abstract}
Many estrogen-receptor- (ER-) expressing breast cancers become refractory to ER-based therapies. New antitumor drugs like aminoflavone (AF) and benzothiazoles (Bzs) have been developed and have exquisite antitumor activity in ER+MCF-7 and T47D cells and in a MCF-7 nude mouse model. ER(-) breast cancer cells like MDA-MB-231 are less susceptible. We previously found in MCF-7 cells that these drugs activate the aryl hydrocarbon receptor (AhR) via translocation to the nucleus, induction of AhRspecific DNA binding activity, and expression of CYP1A1, whose transcription is controlled by the AhR-ARNT transcription factor. CYP1A1 metabolizes AF and Bz to a species which directly or after further metabolism damages DNA. In contrast an AhRdeficient variant of MCF-7 or cells with predominantly nuclear AhR expression, such as MDA-MB 231, are resistant. Thus, these drugs, unlike other neoplastic agents, require AhR-mediated signaling to cause DNA damage. This is a new treatment strategy for breast cancers with intact AhR signaling.
\end{abstract}

\section{Treatment Advances in Breast Cancer}

Metastatic breast cancer is currently incurable, and novel strategies that might become useful treatments are needed. In the past decade, Herceptin directed against the HER2/neu oncoprotein and aromatase antagonists have entered clinical practice $[1,2]$. Despite these advances, cytotoxicity evoked by drugs directed at DNA remains an interesting option [3]. However, these cytotoxics are nonspecific. Ideally, new breast cancer cytotoxics would engage some aspect of breast cancer biology to convey selective toxicity to breast cancer cells.

\section{Aryl Hydrocarbon Receptor}

The aryl hydrocarbon receptor (AhR) was initially defined as a receptor for environmental toxins such as dioxin. It belongs to the helix-loop-helix transcription factor family. Other members of this family are AhR nuclear translocator
(ARNT); Drosophila proteins, SIM and PER, and hypoxiainducible factor $1 \alpha$ (HIF $1 \alpha)$ [4-7]. AhR is a ligand-activated transcription factor. The most commonly known ligands of AhR are polycyclic and polyhalogenated hydrocarbons (benzopyrene, 3-methyl-colantrene), xenobiotics (phenobarbital), and other pesticides like tetrachlorodibenzo-pdioxin (TCDD).

AhR is localized within the cell cytosol constitutively where it is part of an inactivated complex composed of two heat-shock proteins: heat-shock protein 90 (Hsp90) and a $43 \mathrm{kDa}$ protein known as AIP (Figure 1). The role of Hsp90 involves a chaperone activity that keeps AhR in a favorable ligand-binding configuration while it prevents its nuclear translocation. Hydrophobic ligands of AhR enter the cell by simple diffusion and bind to the receptor associated to Hsp90. Ligand binding to the receptor triggers a conformational change in AhR to a form that exhibits stronger affinity for DNA. This event leads to dissociation of the cytoplasmic 


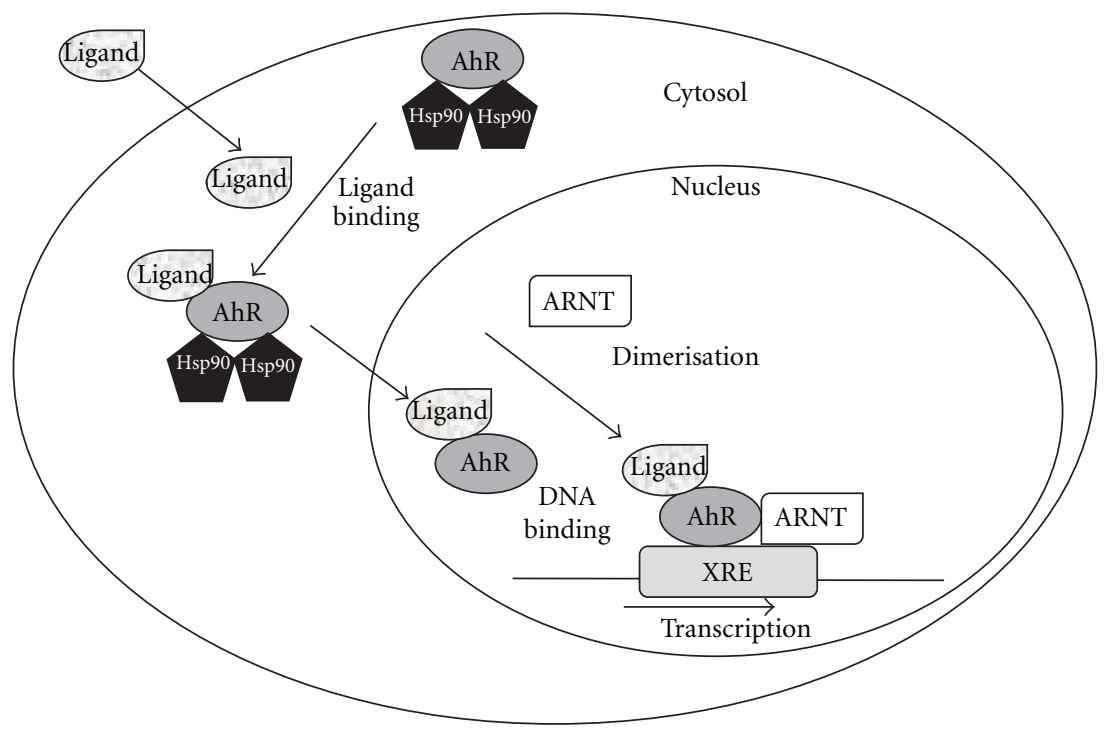

FIGURE 1: The aryl hydrocarbon signaling pathway.

complex and to AhR nuclear translocation. Within the nucleus, AhR interacts with ARNT forming a heterodimer that binds to specific DNA sequences called xenobiotic response elements (XREs). This binding leads to the transcriptional activation of genes that possess these XREs in their promoter sequences. Some of the genes activated by AhR encode phase I and II metabolic enzymes such as cytochrome P450 (CYP) 1A1, CYP1A2, and CYP1B1. AhR activation was first described as a cellular response to promote elimination of ambient contaminants and xenobiotics [8-10]. In humans, AhR is localized in liver, lungs, kidneys, placenta, lymphocytes, ovary, and breast. AhR/ARNT complex activation is tissue-specific and depends on co-regulators present in different cell types [9].

\section{Estrogen Receptor-Aryl Hydrocarbon Receptor Crosstalk}

It was demonstrated that in breast cancer cells, AhR ligands have the capacity to bind to ER and potentially interfere with ER signaling [11]. Also, it has long been known that estrogen can be metabolized by AhR-driven genes such as CYP1B1 to yield toxic metabolites that in some cases have been proposed to act as genotoxins [12]. This has led to the hypothesis that mutual modulation of AhR and ER signaling functions may be possible. Indeed, previous publications have shown that certain AhR ligands can have antiproliferative effects alone or in conjunction with ER antagonist administration with evidence of antitumor activity in breast cancer models [13]. How estrogen and its antagonist will agonize, have no effect, or amplify AhR-related signaling functions is a key unresolved question.

\section{Benzothiazoles and Aminoflavone: AhR-Targeted Therapies for Breast Cancer}

Empirical screening in the NCI cell line anticancer drug screen has revealed two types of molecules, the benzothia- zoles (Bzs) [14-18] and aminoflavone (AF) [19], which are noteworthy for differential cytotoxicity. "Sensitive" cell lines have total growth inhibition (TGI) between 0.1 and $1 \mu \mathrm{M}$, while "resistant" cell lines are refractory to $\mathrm{Bz}$ and $\mathrm{AF}$ concentrations $<10 \mu \mathrm{M}$. Among the consistently sensitive cell lines to both compound classes were the $\mathrm{ER}(+)$ breast cancer cell lines MCF-7 and T47D [18, 19]. While certain other cell types in this screen did show susceptibility, for example, renal cancer, in the breast cancer panel, optimal cytotoxicity of these drugs was seen in cell lines expressing estrogen receptor $(\mathrm{ER}(+))$ [18]. Detailed mechanistic studies for both Bzs and AF have revealed that "sensitive" cells can activate AhR signaling, as might be expected from their planar nature [20]. This causes expression of CYP1A1 and in certain cell lines CYP1B1. Prior work had shown that CYP1A1 can metabolize Bzs and AF to produce DNA-damaging metabolites [14-19].

\section{Benzothiazoles' Mechanism of Action}

Previous results from our research group have demonstrated that the antitumor effect of compounds of the 2-(4-amino3-methylphenyl) benzothiazole group (DF 203, NSC 674495; 5F 203, NSC 703786) (Figure 2) is mediated by AhR in MCF-7 breast tumor cells [15, 17, 21]. Currently Phortress, the lysine amide prodrug of 2-(4-amino-3-methylphenyl)5-fluorobenzothiazole (5F 203), is under Phase I clinical evaluation sponsored by the Cancer Research UK [21-29].

DF 203 preceded 5F 203 in the development of Phortress. A fluorine atom was introduced to thwart deactivating metabolism of DF 203 by CYP1A1 to inactive hydroxylated biotransformation products [23]. We observed that treatment of MCF-7 with Bzs resulted in activation of AhR. Figure 3 shows AhR translocation to the nucleus after treatment with DF 203 in sensitive cells like MCF-7 but not in resistant cells like MDA-MB-435. However, a controversy exists concerning the origin of MDA-MB-435 cells. In the last years it has been shown that these cells are derived from a melanoma [15]. 
<smiles>[R]c1ccc2sc(-c3ccc(N)c(C)c3)nc2c1</smiles>

DF 203 (NSC 674495): $\mathrm{R}=\mathrm{H}$ 5F 203 (NSC 703786): $\mathrm{R}=\mathrm{F}$<smiles>Cc1cc(-c2nc3cc(F)ccc3s2)ccc1NC(=O)[C@H](N)CN</smiles>

Phortress (NSC 710305)

FIgURE 2: Chemical structures of antitumor 2-(4-amino-3-methylphenyl)benzothiazoles.
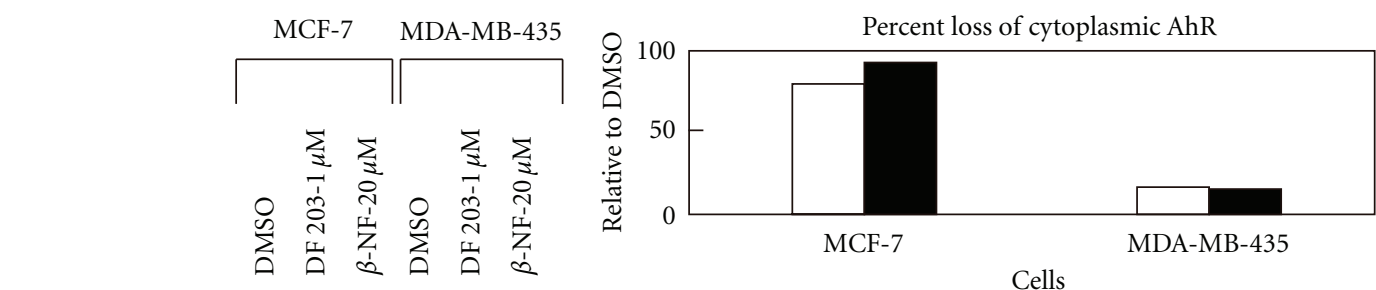

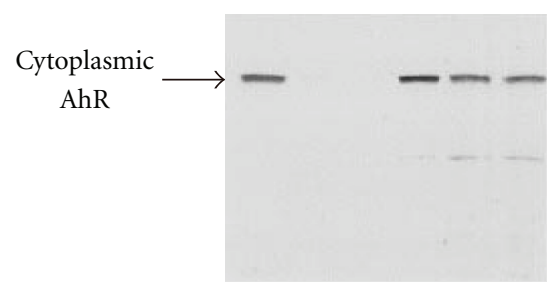

Nuclear AhR

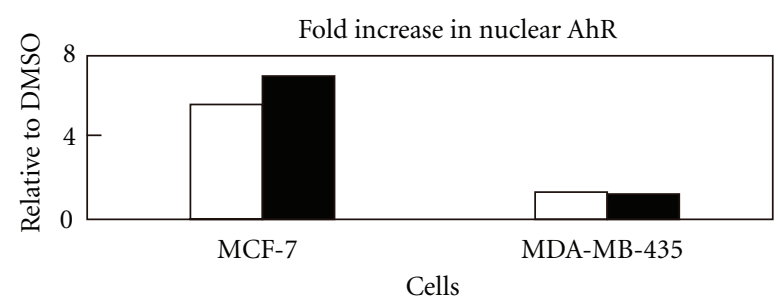

DF 203

$\beta$-NF

FIGURE 3: DF 203 causes an increase in immunoreactive nuclear AhR in MCF-7 cells. MCF-7 and MDA-MB-435 were treated with 0.1\% DMSO, $1 \mu \mathrm{M}$ DF 203, or $20 \mu \mathrm{M} \beta$-naphthoflavone for $1 \mathrm{~h}$. Determination of immunoreactive AhR in cytoplasmic and nuclear fractions was performed by western blot. $\beta$-NF: $\beta$-naphthoflavone [15].

In a similar way when we used 5F 203 we observed an increase in AhR transcriptional activity (increase in XRE-luciferase activity (Figure 4(a)) and formation of protein/DNA complexes bound to XRE Figure 4(b)) [17].

We also observed an increase in the transcription of AhR target genes such as CYP1A1/1B1, but AHR 100 cells, derived from MCF-7 which do not express the AhR receptor,

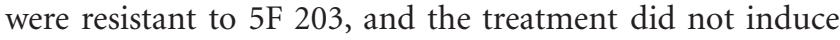
activation of CYP1A1 (Figure 5) [17].

We also demonstrated that in MCF-7 cells, treatment with 5F 203 prevents entry into G2/M and S phase and causes apoptosis, which was not observed in AHR 100 cells (Figure 6) [17]. These data suggested that activation of AhR was necessary for the antitumor activity of the benzothiazoles in MCF-7.

The mechanism of action of benzothiazoles is represented in Figure 7.

\section{Aminoflavone, an Alternative Therapy for ER+ Breast Cancer Cell Lines Resistant to Antihormone Treatment}

AF (NSC 686288) is a novel anticancer agent (Figure 8). Previous work from our research group demonstrated that $\mathrm{AF}$ is a ligand of AhR [19]. It was proposed that induction of
CYP1A1 and high covalent binding of AF metabolites are markers to predict sensitivity to this drug in breast and renal tumors $[19,20]$. AF derivative compound, aminoflavone prodrug (AFP464, NSC710464), has currently entered phase II clinical trials (Figure 8).

AF activity has been linked to the presence of cytoplasmic AhR and nuclear translocation of the AhR-AF complex followed by induction of cytochrome P450 (CYP) 1A1, activation of sulfotransferase 1A1 (SULT1A1), and DNA damage caused by metabolites. The latter is exemplified by the occurrence of gamma-histone $2 \mathrm{AX}(\mathrm{H} 2 \mathrm{AX})$ phosphorylation consistent with induction of DNA single-strand breaks and DNA-protein cross-links (Figure 9) [30].

AF has shown exquisite in vitro sensitivity toward estrogen-receptor-positive (ER+) breast cancer cell lines and in vivo activity in MCF-7 xenografts (Figure 10) [19].

In contrast, ER- breast cancer cell lines, like MDA-MB431, were resistant to AF. Crosstalk between AhR and ER signaling pathways has been established. It was shown that ligand-bound AhR can mimic estrogens and redirect ER from ER target genes to AhR target genes, such as CYP1A1 [13]. Given these facts, patients that might benefit most from AF treatment in the clinic could be those with ER+, endocrine-therapy-resistant breast cancers. 

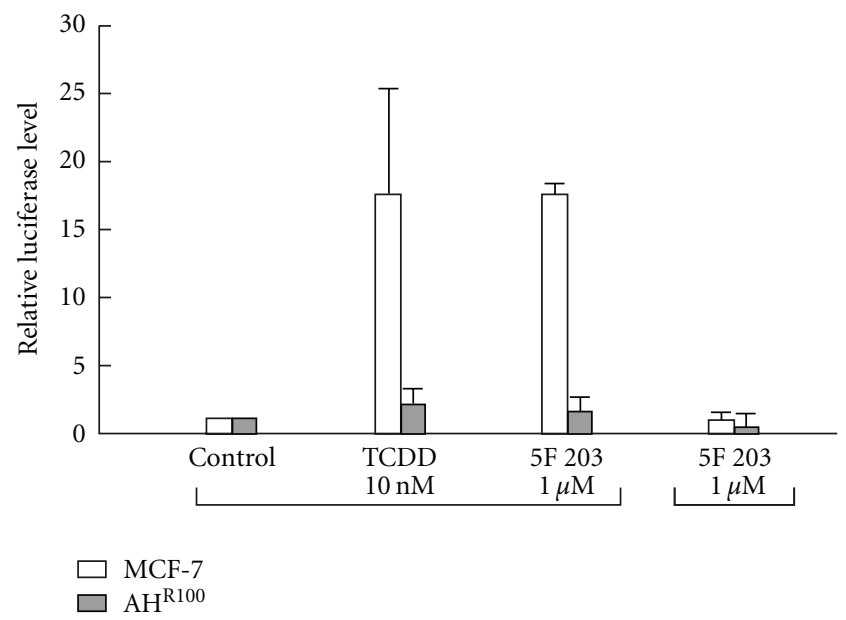

(a)

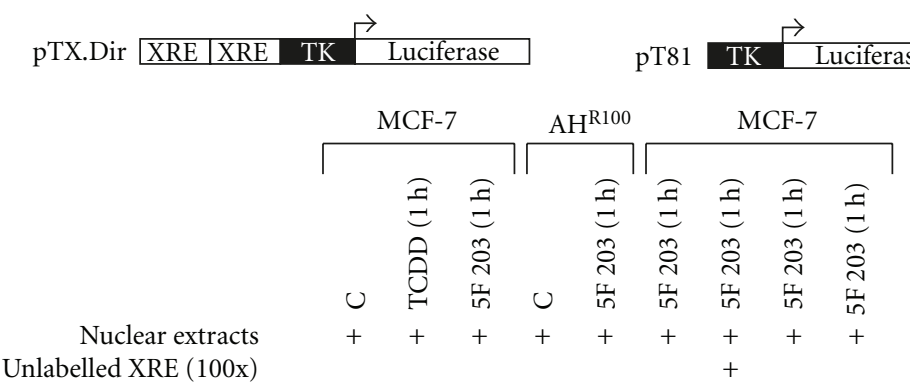

Ab. AhR

Labelled XRE

Unlabelled Sp1 (100x)
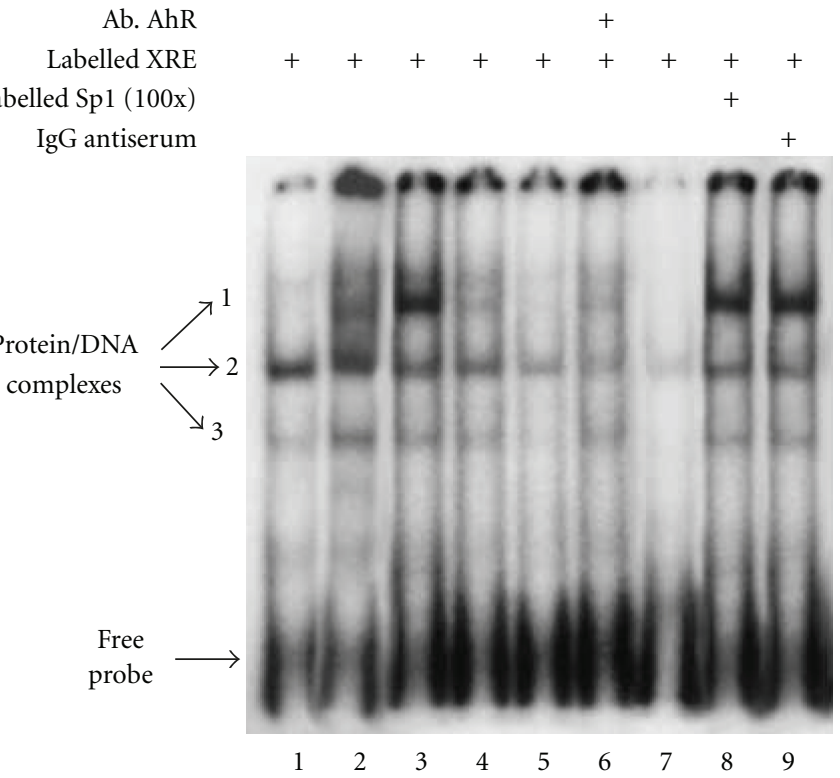

(b)

FIgURE 4: (a) 5F 203 induces binding to the XRE sequence of CYP1A1. MCF-7 and AHR100 cells were transfected with XRE-luciferase (pTX.Dir.) or pT81. A schematic of the respective construct is shown below the panel. Transfected cells were treated with DMSO, TCDD $(10 \mathrm{nM})$, or 5F $203(1 \mu \mathrm{M})$ for $9 \mathrm{~h}$. XRE-luciferase activity was determined normalizing to the amount of Renilla reniformis luciferase. The values are expressed as luciferase levels relative to control. (b) 5F 203 induces protein/DNA complexes on the XRE sequence of the CYP1A1 promoter. Nuclear extracts $(20 \mathrm{mg})$ prepared from MCF-7 cells treated with $0.1 \%$ DMSO control (lane 1$)$, TCDD (10 nM, $1 \mathrm{~h})($ lane 2$)$, or 5F $203(1 \mu \mathrm{M}, 1 \mathrm{~h})$ (lane 3) were incubated with labeled XRE sequence derived from the CYP1A1 promoter for 10 min at room temperature. Free DNA and bound DNA were separated as described. In competition experiments, nuclear extracts from MCF-7 cells treated with 5F $203(1 \mu \mathrm{M}, 1 \mathrm{~h})$ were incubated with $4 \mu \mathrm{g}$ of anti-AhR antibody (lane 6), 100-fold excess of unlabeled XRE oligonucleotide (lane 7), 100-fold excess of unlabeled Sp1 oligonucleotide (lane 8), or $4 \mu \mathrm{g}$ of IgG antiserum (lane 9). Protein/DNA complexes from AHR100 cells were resolved in the same gel. Nuclear extracts from these cells $(20 \mathrm{mg})$ treated with DMSO (lane 4) or 5F $203(1 \mu \mathrm{M}, 1 \mathrm{~h})$ (lane 5) were incubated with radioactive XRE and resolved by the same procedure [17]. 


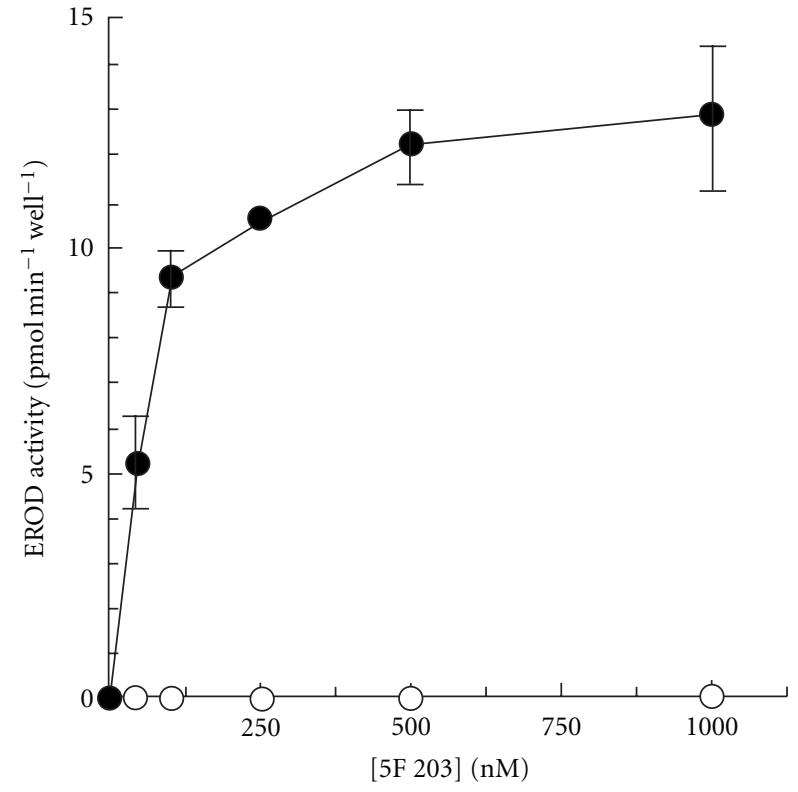

MCF-7 $\mathrm{AH} \mathrm{R}^{\mathrm{R} 100}$

(a)

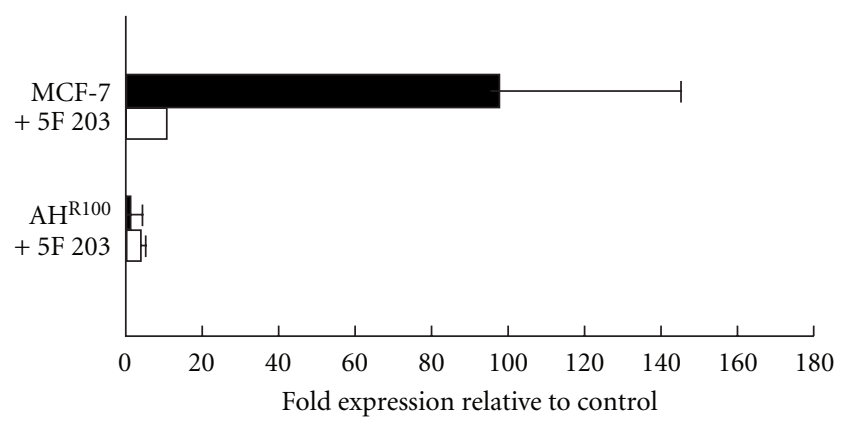

CYP1A1

CYP1B1

(b)

Figure 5: (a) 5F 203 induces CYP1A1 activity in MCF-7 but not in $\mathrm{AH}^{\mathrm{R} 100}$ cells. MCF-7 and AHR100 cells were incubated for $24 \mathrm{~h}$ with DMSO $(0.1 \%)$ and 5F $203(1 \mu \mathrm{M})$ for $24 \mathrm{~h}$ and assayed for CYP1A1 enzyme activity by EROD assay, $n=4 \pm$ s.d. (b) 5F 203 induces CYP1A1 and CYP1B1 mRNA levels in sensitive (MCF-7) cells. MCF-7 and AHR100 cells were treated with 5F $203(1 \mu \mathrm{M})$ for $24 \mathrm{~h}$, RNA was isolated from control and treated samples, and CYP1A1 and CYP1B1 gene expression were measured by real-time RT-PCR as described. Data are shown as fold induction of treated cells relative to constitutive expression in control cells \pm s.d., $n=7$ (samples from two independent experiments) [17].

Recent work was performed to test whether breast cancers resistant to antihormone treatments retain sensitivity to AF. The AF response in a panel of molecularly well defined breast cancer cell lines was evaluated. The latter included MCF-7 (ER+) and its resistant subclones MCF-7/Her2-18 $(\mathrm{ER}+)$, MCF-7TAM1 (ER+), LTLC (ER+high), and LTLT $\left(\mathrm{ER}^{\text {very low }}\right)$; T47D (ER+), MDA-MB-231 (ER-); Hs5718ti8
(ER-); MCF10A (ER-). Antiproliferative effects were measured by MTT assay, and concentrations that inhibit cell growth by $50 \%\left(\mathrm{IC}_{50}\right)$ of the control were established for each cell line. The response to AF was compared to ER and AhR expression by western blot and immunocytochemistry. AF potently inhibited the growth of all ER+ breast cancer cell lines at nanomolar concentrations irrespective of hormone resistance $\left(\right.$ mean IC $_{50}$ s: MCF-7 $=16 \mathrm{nM}$; MCF-7/Her2-18 = $20 \mathrm{nM}$; MCF-7TAM $1=25 \mathrm{nM}$; T47D $=14 \mathrm{nM}$; LTLC $=$ $100 \mathrm{nM}$ ), whereas the ER- breast cancer cell lines (mean IC $_{50}$ s: MDA-MB-231 $=25 \mu \mathrm{M}$; Hs5718ti8 $=18 \mu \mathrm{M}$; LTLT $>50 \mu \mathrm{M})$ and the ER- breast epithelial line MCF10A $\left(\mathrm{IC}_{50}=\right.$ $3 \mu \mathrm{M}$ ) were 2- to 3-log-fold less sensitive. Interestingly, AhR was predominantly localized in the nuclei of all ER- cell lines, but was expressed in the cytoplasm of ER+ cells. MCF7/Her2-18 and MCF-7TAM1, which are both tamoxifen-resistant subclones of MCF-7 ( $\mathrm{IC}_{50} \mathrm{~s} 4-\mathrm{OH}-$ tamoxifen 3 and $10 \mu \mathrm{M})$ and LTLC, a letrozole-resistant clone ( IC $_{50}>1 \mu \mathrm{M}$ ), retained a sensitivity to AF that was similar to parental MCF7 cells [31,32].

In order to examine the role of $\mathrm{ER}$ in $\mathrm{AF}$ sensitivity, $\mathrm{AF}$ was combined with a fixed concentration $(100 \mathrm{nM})$ of the "pure" antiestrogen Faslodex in MCF-7 cells. The $\mathrm{IC}_{50}$ for AF plus Faslodex was found to be $0.5 \mathrm{nM}$, suggesting a synergism between the two drugs. To further prove that ER-AhR crosstalk is correlated with AF sensitivity, MDA-MB-231 cells (ER-) were stably transfected with human estrogen receptor- $\alpha$, rendering them ER+. It was found that the ER+ MDAMB-231 cells had cytoplasmic AhR and were 5 times more sensitive to $\mathrm{AF}\left(\mathrm{IC}_{50}=5 \mu \mathrm{M}\right)$ compared to parental- and vector-transfected cells.

The authors concluded that the cytoplasmic AF-AhR complex can activate unliganded ER to enhance AhR target gene expression $[31,32]$.

\section{Vorinostat Can Sensitize Triple Negative Breast Cancer Cell Lines to Aminoflavone Prodrug}

AFP464 exhibits differential in vitro cytotoxicity in breast cancer cell lines with inhibitory $50 \%\left(\mathrm{IC}_{50}\right)$ concentrations ranging from 0.01 to $30 \mu \mathrm{M}$. AFP464 plasma levels that can safely be reached in patients are $\sim 1 \mu \mathrm{M}$. In sensitive cells, AFP464 induces AhR-mediated cytochrome P450- (CYP-) dependent xenobiotic response and cell death. In resistant cells, the CYP system was not induced. Recent experiments showed that a panel of 10 luminal and basal A type breast cancer cells irrespective of resistance to antihormone therapies (e.g., tamoxifen refractory MCF7TAM1 cells) were exquisitely sensitive to AFP464 with $\mathrm{IC}_{50}$ s between 0.01 and $0.025 \mu \mathrm{M}$, whereas "triple-negative" breast cancer (TNBC) cell lines with a basal B-like gene cluster were resistant $[33,34]$. Drug concentrations needed to inhibit the growth of basal B-like cells by $50 \%(25-30 \mu \mathrm{M})$ may not be achieved in patients. Thus, it was proposed that in TNBCs, combination treatments will be needed and that agents modifying gene transcription, such as the histone deacetylase inhibitor, vorinostat, might be suitable combination partners. To test 

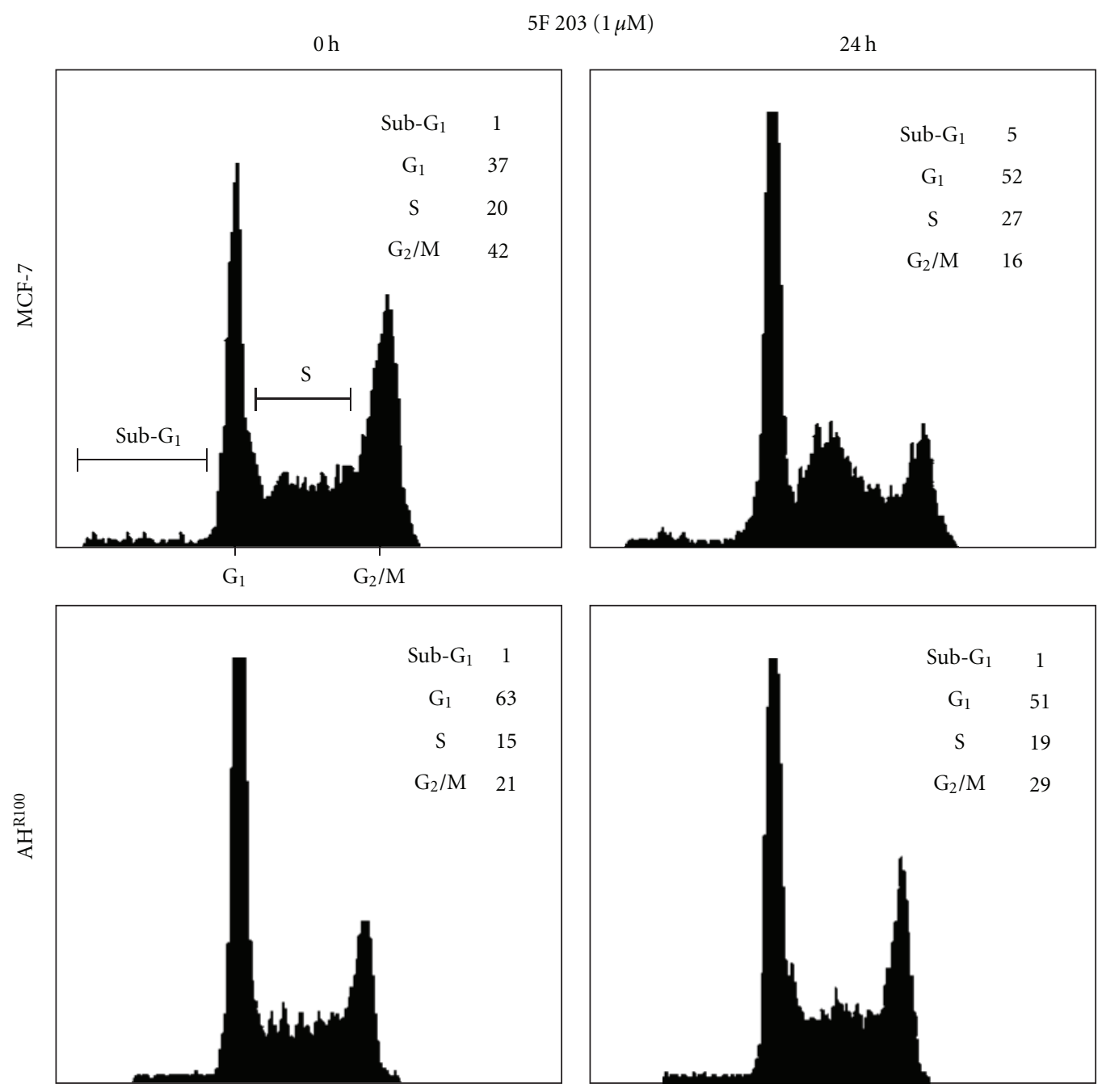

FIgURE 6: 5F 203 induces some accumulation of cells in S phase. Exponentially growing cells (MCF-7 and AHR100) were exposed to either $0.1 \%$ DMSO (control) or 5F $203(1 \mu \mathrm{M})$ for $24 \mathrm{~h}$, harvested, washed in PBS, and fixed in $70 \%$ ethanol. DNA was stained by incubating the cells in PBS containing propidium iodide, and fluorescence was measured and analysed [17].

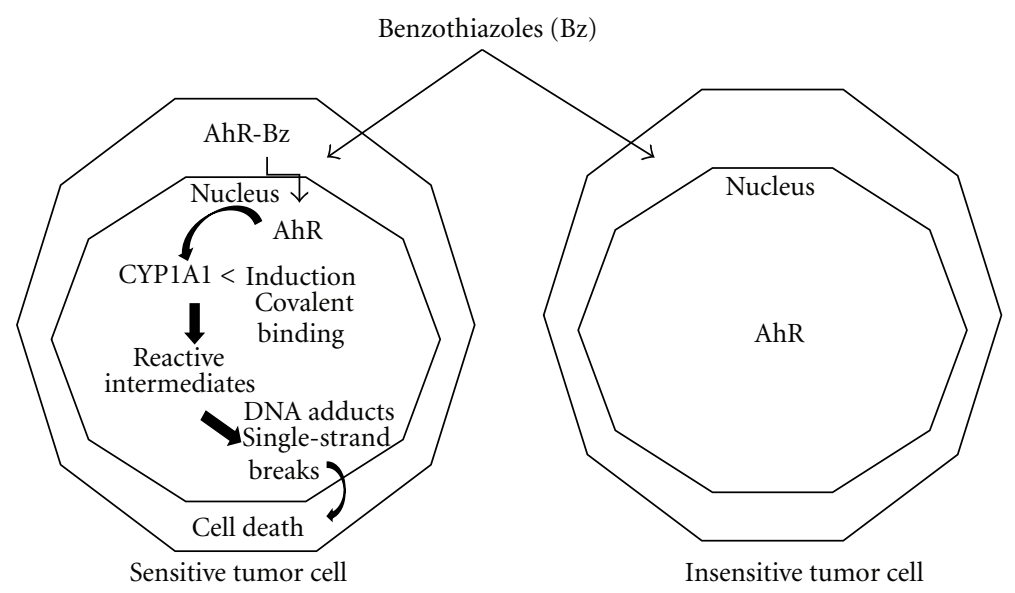

Figure 7: Mechanism of action of benzothiazoles. 
<smiles>Cc1c(F)c(N)c2c(=O)cc(-c3ccc(N)c(F)c3)oc2c1F</smiles>

Aminoflavone (NSC 686288)<smiles>Cc1c(F)c(N)c2c(=O)cc(-c3ccc(NC(=O)[C@@H](N)CCCCN)c(F)c3)oc2c1F</smiles>

AFP464 (NSC 710464)

FIgURE 8: Aminoflavones's structures.

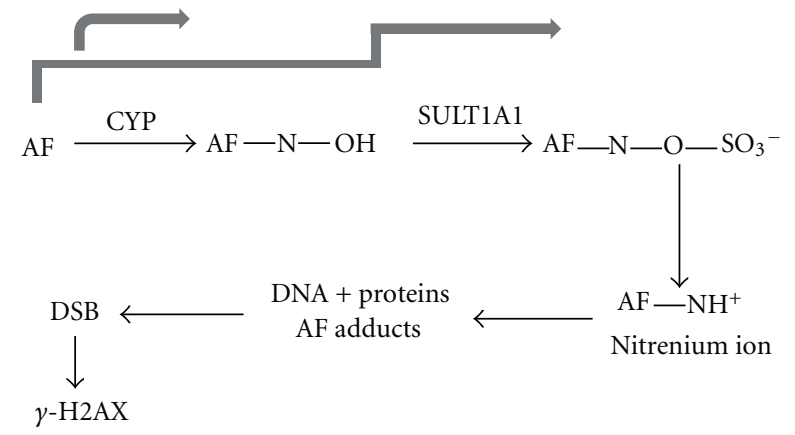

Figure 9: Mode of action of aminoflavone. Aminoflavone binds to cytosolic AhR. Only breast cancer cells with cytosolic AhR form AhR: AF complexes that translocate to the nucleus. Cells with constitutive nuclear AhR expression are not influenced by AF. In the nucleus, AhR: AF complex induces CYP1A1 leading to AF metabolism and DNA-damaging products. AF-sensitive breast cancer cells examined to this point express estrogen receptor (ER). SULT1A1: sulfotransferase 1A1; DSB: double strand breaks [30].

this hypothesis, combination experiments were employed using the fixed $\mathrm{IC}_{50}$ ratio method and treated MDA-MB-231 and Hs578T cells were treated for 24,48 , and $72 \mathrm{hrs}$ with vorinostat followed by AFP464 for a total of 5 days. It was found that AFP464 and vorinostat can act synergistically; in Hs578T cells, combination indices (CIs) of $<0.3$ were seen after pretreatment with vorinostat for $24 \mathrm{hrs}$, reducing the AFP464 $\mathrm{IC}_{50}$ from $20 \mu \mathrm{M}$ to $0.5 \mu \mathrm{M}$; in MDA-MB-231 cells, CIs indicating synergism $(<1)$ were observed when adding AFP464 after 48 and $72 \mathrm{hrs}$ pretreatment with vorinostat. This led to a 25 -fold sensitization to AFP464 $\left(\mathrm{IC}_{50}=1 \mu \mathrm{M}\right)$ $[33,34]$.

To study mechanisms that could explain the sensitization of TNBC cell lines to AFP464, real-time PCR to assess the induction of CYP1A1 and CYP1B1 after vorinostat treatment, western blotting to determine estrogen receptor reactivation, and transcriptional profiling using Illumina Human HT-12 v3 whole-genome expression BeadChips were performed. In MDA-MB-231 cells vorinostat treatment restored the AhR-dependent xenobiotic response to AFP464 by in- ducing both CYP1A1 and B1; also estrogen receptor expression was detectable in MDA-MB-231 and Hs578T cells at the protein level, consistent with driving these TNBCs into a more luminal-like genotype. These data indicated the usefulness of gene expression profiling in selecting patients for AFP464 treatment. While single agent therapy might present an option for hormone refractory luminal and basal A type patient populations, breast cancer patients with basal B-like tumors will require combination therapies, for example, with vorinostat. Pretreatment of TNBCs with vorinostat could sensitize these tumors to AFP464 [34].

\section{Nuclear Expression of the Aryl Hydrocarbon Receptor Elicits Resistance to Aminoflavone Prodrug}

Other studies were performed to test whether primary human tumors would also show nuclear or cytoplasmic AhR and to assess the extent to which AhR was expressed. 165 archival human tissues were analyzed comprising breast, pancreas, ovarian, and renal cell cancers. It was found that the 59 percent of all cases had detectable AhR, amongst those 78 percent exhibited cytoplasmic AhR and 22 percent nuclear AhR. Pancreatic (70\%) and breast cancers (46\%) showed the highest percentage of cytoplasmic AhR [34].

Together these data indicate that AhR has a distinct distribution pattern in tumor cells. Cytoplasmic AhR expression elicits sensitivity to the AhR ligand AFP464. If AhR is located in the nucleus, the xenobiotic response is impaired and AFP464 cannot be activated [35].

\section{Conclusions}

These results lead one to the conclusion that AF and Bzs, two structurally dissimilar compounds, share certain characteristics in their mechanism of action but are certainly not identical in their pattern of activity. Both compounds activate the AhR signaling pathway leading to an increase in CYP1A1 and CYP1B1 gene expression in drug-sensitive MCF-7 cells but not in resistant cells like MDA-MB-435, PC-3, or MCF-7 AhR-deficient AHR100 cells. Although activation of 


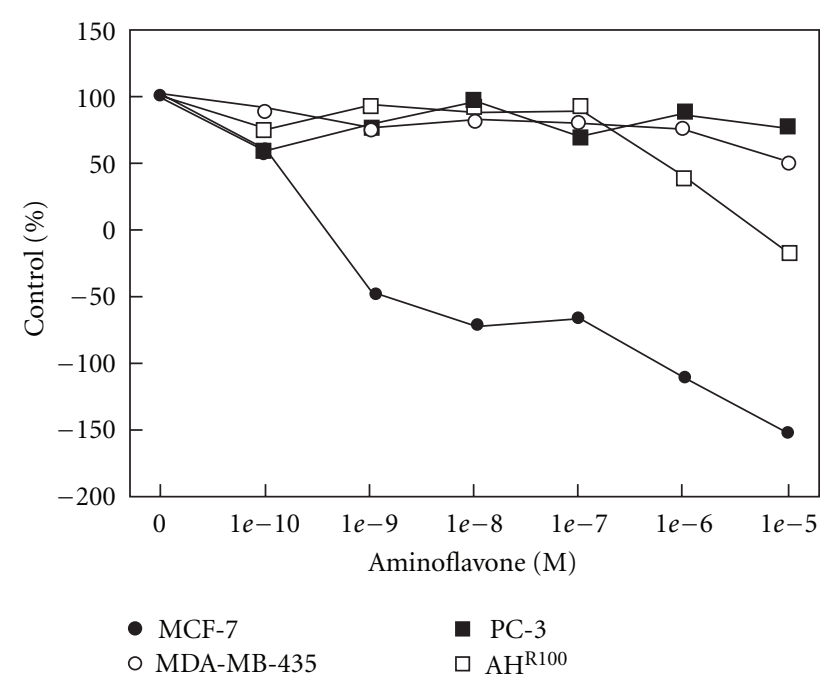

(a)

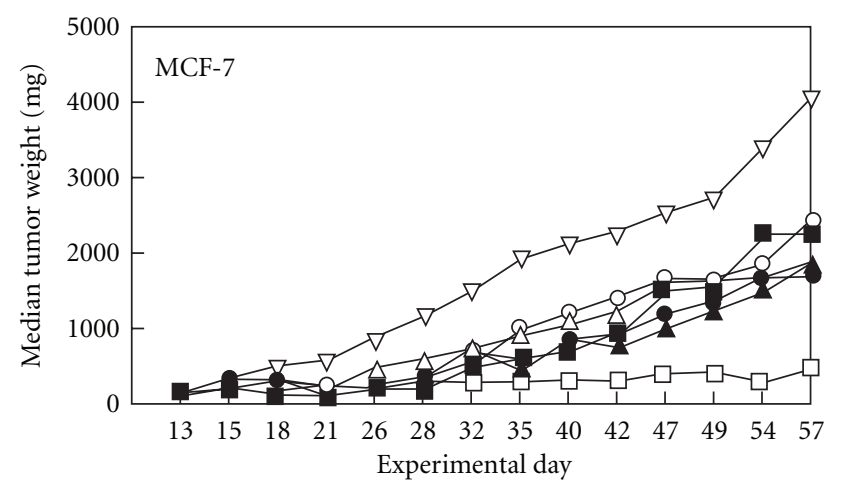

$\begin{array}{ll}\nabla \text { Vehicle IP } & \text { — } 90 \mathrm{mg} / \mathrm{kg} \mathrm{IV} \\ \square 120 \mathrm{mg} / \mathrm{kg} \mathrm{IP} & \Delta 60 \mathrm{mg} / \mathrm{kg} \mathrm{IV} \\ \triangle 80 \mathrm{mg} / \mathrm{kg} \mathrm{IP} & \bullet 40 \mathrm{mg} / \mathrm{kg} \mathrm{IV} \\ \bigcirc 53 \mathrm{mg} / \mathrm{kg} \mathrm{IP} & \end{array}$

(b)

Figure 10: Cytotoxicity of aminoflavone in vitro and in vivo. (a) Selective cytotoxicity of aminoflavone to MCF-7 breast tumor cells. Cell lines were seeded into 24 -well plates and allowed to grow for 48 hours. Cells were treated with $10^{-10}$ to $10^{-5} \mathrm{~mol} / \mathrm{L}$ aminoflavone for an additional 72 hours. Cell monolayers were stained with sulforhodamine (b) and protein was determined spectrophotometrically. Points, mean \pm SD $(n=10)$. SD was $<5 \%$ for all drug concentrations and was omitted for purpose of graphical clarity. (b) Antitumor activity of aminoflavone against MCF-7 breast tumor xenografts. Treatments were given on a QD $\times$ 5 schedule beginning on day 13 . There were 20 mice in the vehicle control group and 6 mice per dose of aminoflavone in the treated groups [19].

the AhR signaling pathway by the drugs may be necessary for increases in CYP1A1 and CYP1B1 gene expression, additional metabolic conversions may be necessary to produce cytotoxicity. These results suggest that the cytotoxicity of AF and $\mathrm{Bz}$ in a sensitive breast tumor cell line is the result of the engagement of AhR-mediated signal transduction [17, 19]. Thus, these drugs, unlike other neoplastic agents, require
AhR-mediated signaling to cause DNA damage. This offers a new potential treatment strategy for breast cancers with intact AhR signaling. Induction of CYP1A1 and AhR activation were considered as markers to predict sensitivity of tumors to $\mathrm{Bz}$ and $\mathrm{AF}$ treatment in Phase I clinical trials.

The data presented in this paper indicate that the cytoplasmic AF-AhR complex can activate unliganded ER to enhance AhR target gene expression and as a result AF cytotoxicity [32]. Therefore, Phase II clinical trials of AF should include hormone-resistant, metastatic breast cancers.

Also, these data indicated the usefulness of gene expression profiling in selecting patients for AF treatment. While single-agent therapy might present an option for hormone refractory luminal and basal A type patient populations, breast cancer patients with basal B-like tumors will require combination therapies, for example, with vorinostat $[33,34]$. Pretreatment of TNBCs with vorinostat could sensitize these tumors to AF, and this should be exploited in clinical trials.

AhR has a distinct distribution pattern in tumor cells. Cytoplasmic AhR expression elicits sensitivity to the AhR ligand AF. If AhR is located in the nucleus, xenobiotic response is impaired and AF cannot be activated [35]. Thus, immunohistological analysis of AhR should also be considered as a tool in the upcoming Phase II trials in breast cancer to select patients that are most likely to benefit from AF treatment.

\section{References}

[1] K. Altundag, F. J. Esteva, and B. Arun, "Monoclonal antibodybased targeted therapy in breast cancer," Current Medicinal Chemistry, vol. 5, no. 2, pp. 99-106, 2005.

[2] A. Brodie, "Aromatase inhibitor development and hormone therapy: a perspective," Seminars in Oncology, vol. 30, no. 4, supplement 14, pp. 12-22, 2003.

[3] S. Carrick, S. Parker, N. Wilcken et al., "Single agent versus combination chemotherapy for metastatic breast cancer," Cochrane Database of Systematic Reviews, no. 2, Article ID CD003372, 2009.

[4] J. McGuire, P. Coumailleau, M. L. Whitelaw et al., "The basic helix-loop-helix/PAS factor Sim is associated with hsp90: implications for regulation by interaction with partner factors," Journal of Biological Chemistry, vol. 270, no. 52, pp. 31353-31357, 1995.

[5] B. N. Fukunaga, M. R. Probst, S. Reisz-Porszasz, and O. Hankinson, "Identification of functional domains of the aryl hydrocarbon receptor," Journal of Biological Chemistry, vol. 270, no. 49, pp. 29270-29278, 1995.

[6] C. Antonsson, M. L. Whitelaw, J. McGuire et al., "Distinct roles of the molecular chaperone hsp90 in modulating dioxin receptor function via the basic helix-loop-helix and PAS domains," Molecular and Cellular Biology, vol. 15, no. 2, pp. 756-765, 1995.

[7] G. L. Wang, B. H. Jiang, E. A. Rue, and G. L. Semenza, "Hypoxia-inducible factor 1 is a basic-helix-loop-helix-PAS heterodimer regulated by cellular $\mathrm{O}_{2}$ tension," Proceedings of the National Academy of Sciences of the United States of America, vol. 92, no. 12, pp. 5510-5514, 1995.

[8] J. C. Rowlands and J. A. Gustafsson, "Aryl hydrocarbon receptor-mediated signal transduction," Critical Reviews in Toxicology, vol. 27, no. 2, pp. 109-134, 1997. 
[9] J. P. Whitlock Jr., "Induction of cytochrome P4501A1," Annual Review of Pharmacology and Toxicology, vol. 39, pp. 103-125, 1999.

[10] T. D. Bradshaw, V. Trapani, D. A. Vasselin, and A. D. Westwell, "The aryl hydrocarbon receptor in anticancer drug discovery: friend or foe?" Current Pharmaceutical Design, vol. 8, no. 27, pp. 2475-2490, 2002.

[11] M. S. Denison and S. R. Nagy, "Activation of the Aryl hydrocarbon receptor by structurally diverse exogenous and endogenous chemicals," Annual Review of Pharmacology and Toxicology, vol. 43, pp. 309-334, 2003.

[12] J. G. Liehr, "Is estradiol a genotoxic mutagenic carcinogen?" Endocrine Reviews, vol. 21, no. 1, pp. 40-54, 2000.

[13] S. Safe, C. Qin, and A. McDougal, "Development of selective aryl hydrocarbon receptor modulators for treatment of breast cancer," Expert Opinion on Investigational Drugs, vol. 8, no. 9, pp. 1385-1396, 1999.

[14] M. S. Chua, E. Kashiyama, T. D. Bradshaw et al., "Role of CYP1A1 in modulation of antitumor properties of the novel agent 2-(4-amino-3-methylphenyl)benzothiazole (DF 203, NSC 674495) in human breast cancer cells," Cancer Research, vol. 60, no. 18, pp. 5196-5203, 2000.

[15] A. I. Loaiza-Pérez, V. Trapani, C. Hose et al., "Aryl hydrocarbon receptor mediates sensitivity of MCF-7 breast cancer cells to antitumor agent 2-(4-Amino-3-methylphenyl) benzothiazole," Molecular Pharmacology, vol. 61, no. 1, pp. 13-19, 2002.

[16] A. Monks, E. Harris, C. Hose et al., "Genotoxic profiling of MCF-7 breast cancer cell line elucidates gene expression modifications underlying toxicity of the anticancer drug 2-(4-amino-3-methylphenyl)-5-fluorobenzothiazole," Molecular Pharmacology, vol. 63, no. 3, pp. 766-772, 2003.

[17] V. Trapani, V. Patel, C. O. Leong et al., "DNA damage and cell cycle arrest induced by 2-(4-amino-3-methylphenyl)-5fluorobenzothiazole (5F 203, NSC 703786) is attenuated in aryl hydrocarbon receptor deficient MCF-7 cells," British Journal of Cancer, vol. 88, no. 4, pp. 599-605, 2003.

[18] C. D. Hose, M. Hollingshead, E. A. Sausville, and A. Monks, "Induction of CYP1A1 in tumor cells by the antitumor agent 2-[4-amino-3-methylphenyl]-5-fluoro-benzothiazole: a potential surrogate marker for patient sensitivity," Molecular Cancer Therapeutics, vol. 2, no. 12, pp. 1265-1272, 2003.

[19] A. I. Loaiza-Pérez, S. Kenney, J. Boswell et al., "Aryl hydrocarbon receptor activation of an antitumor aminoflavone: basis of selective toxicity for MCF-7 breast tumor cells," Molecular Cancer Therapeutics, vol. 3, no. 6, pp. 715-725, 2004.

[20] A. I. Loaiza-Pérez, S. Kenney, J. Boswell et al., "Sensitivity of renal cell carcinoma to aminoflavone: role of CYP1A1," The Journal of Urology, vol. 171, no. 4, pp. 1688-1697, 2004.

[21] R. Bazzi, T. Bradshaw, C. Rowlands et al., "2-(4-Amino-3methylphenyl)-5-fluorobenzothiazole is a ligand and shows species-specific partial agonism of the aryl hydrocarbon receptor," Toxicology and Applied Pharmacology, vol. 237, no. 1, pp. 102-110, 2009.

[22] T. D. Bradshaw, E. L. Stone, V. Trapani et al., "Mechanisms of acquired resistance to 2-(4-Amino-3-methylphenyl) benzothiazole in breast cancer cell lines," Breast Cancer Research and Treatment, vol. 110, no. 1, pp. 57-68, 2008.

[23] I. Hutchinson, M. S. Chua, H. L. Browne et al., "Antitumor benzothiazoles. 14. Synthesis and in vitro biological properties of fluorinated 2-(4-aminophenyl)benzothiazoles," Journal of Medicinal Chemistry, vol. 44, no. 9, pp. 1446-1455, 2001.

[24] C. O. Leong, M. Suggitt, D. J. Swaine et al., "In vitro, in vivo, and in silico analyses of the antitumor activity of 2-(4-amino3-methylphenyl)-5-fluorobenzothiazoles," Molecular Cancer Therapeutics, vol. 3, no. 12, pp. 1565-1575, 2004.
[25] T. D. Bradshaw, M. S. Chua, H. L. Browne et al., "In vitro evaluation of amino acid prodrugs of novel antitumour 2(4-amino-3-methylphenyl)benzothiazoles," British Journal of Cancer, vol. 86, no. 8, pp. 1348-1354, 2002.

[26] T. D. Bradshaw, I. Fichtner, M. J. Bibby et al., "Preclinical evaluation of amino acid prodrugs of novel antitumor 2(4-amino-3-methylphenyl)benzothiazoles," Molecular Cancer Therapeutics, vol. 1, no. 4, pp. 239-246, 2002.

[27] C. O. Leong, M. Gaskell, E. A. Martin et al., "Antitumour 2-(4-aminophenyl)benzothiazoles generate DNA adducts in sensitive tumour cells in vitro and in vivo," British Journal of Cancer, vol. 88, no. 3, pp. 470-477, 2003.

[28] E. Kashiyama, I. Hutchinson, M. S. Chua et al., "Antitumor benzothiazoles. 8. Synthesis, metabolic formation, and biological properties of the $C$ - and $N$-oxidation products of antitumor 2-(4-aminophenyl)-benzothiazoles," Journal of $\mathrm{Me}$ dicinal Chemistry, vol. 42, no. 20, pp. 4172-4184, 1999.

[29] http://www.cancerresearchuk.org.

[30] L. Meng, Z. Meng, Z. H. Miao et al., "Cytokeratin-RNA crosslinking mediated by the antitumor aminoflavone, 5-amino-2,3-fluorophenyl-6,8-difluoro-7-methyl-4H-1-benzopyran-4-one," Journal of Pharmacology and Experimental Therapeutics, vol. 325, no. 2, pp. 674-680, 2008.

[31] M. K. Wilson, E. Stone, M. Vitolo et al., "Response of breast cancer cell lines to aminoflavone (NSC 686288) is asso-ciated with histone $\mathrm{H} 2 \mathrm{AX}$ phosphorylation and estrogen receptor expression," in Proceedings of the 97th Annual Meeting American Association for Cancer Research, vol. 47, Washington, DC, USA, April 2006, abstract 555.

[32] P. Shelton, E. Sausville, T. Nakanishi et al., "Breast cancer cells resistant to anti-hormone treatments retain sensitivity to Aminoflavone (NSC 686288)," in Proceedings of the AACRNCI-EORTC International Conference: Molecular Targets and Cancer Therapeutics, San Francisco, Calif, USA, 2007.

[33] K. Stark, P. Shelton, D. Gorski et al., "Vorinostat can sensitize triple negative breast cancer cell lines to Aminoflavone Prodrug," in Proceedings of the 100th Annual Meeting of the American Association for Cancer Research, vol. 20, p. 279, Denver, Colo, USA, April 2009.

[34] P. M. Shelton, B. Nguyen, A. Chen, and A. M. Burger, "Transcriptional gene expression profiles indicate response of breast cancer cell lines to aminoflavone prodrug," Cancer Research, vol. 69, supplement 2, p. 2153, 2009.

[35] K. Stark, B. Nguyen, P. Shelton et al., "Nuclear expression of the aryl hydrocarbon receptor elicits resistance to aminoflavone prodrug," in Proceedings of the 101th Annual Meeting American Association for Cancer Research, vol. 2765, Philadelphia, Pa, USA, April 2010. 


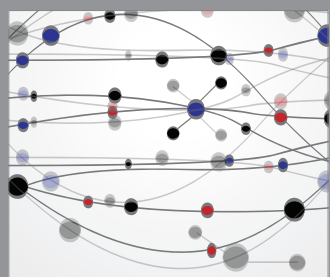

The Scientific World Journal
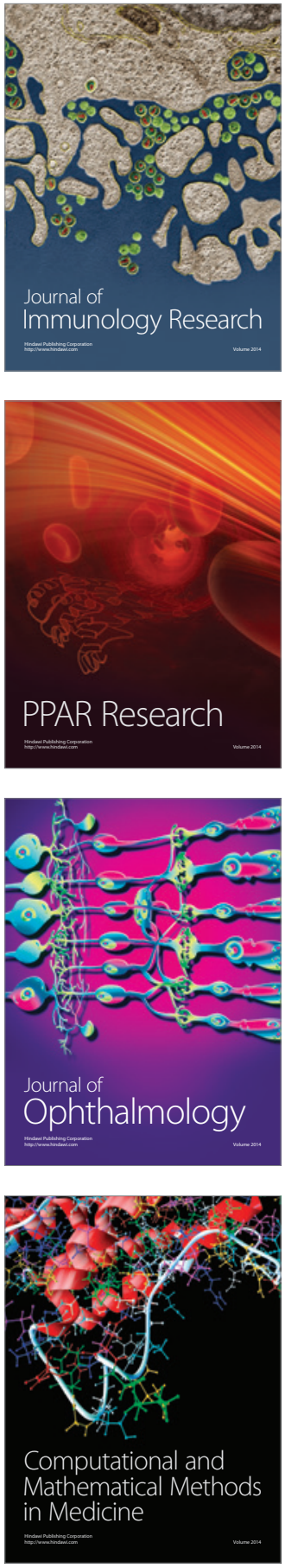

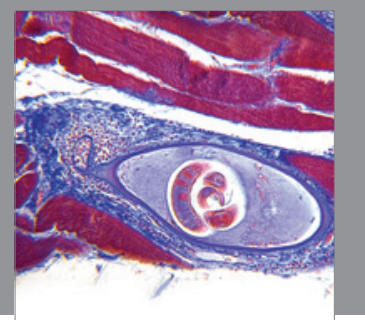

Gastroenterology

Research and Practice
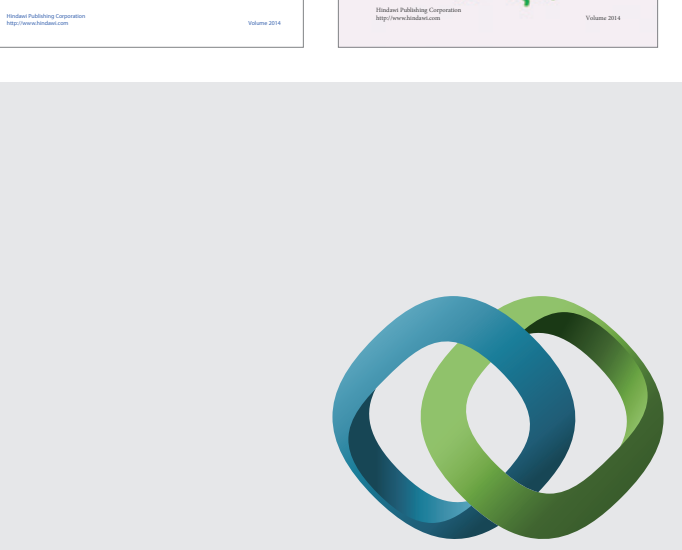

\section{Hindawi}

Submit your manuscripts at

http://www.hindawi.com
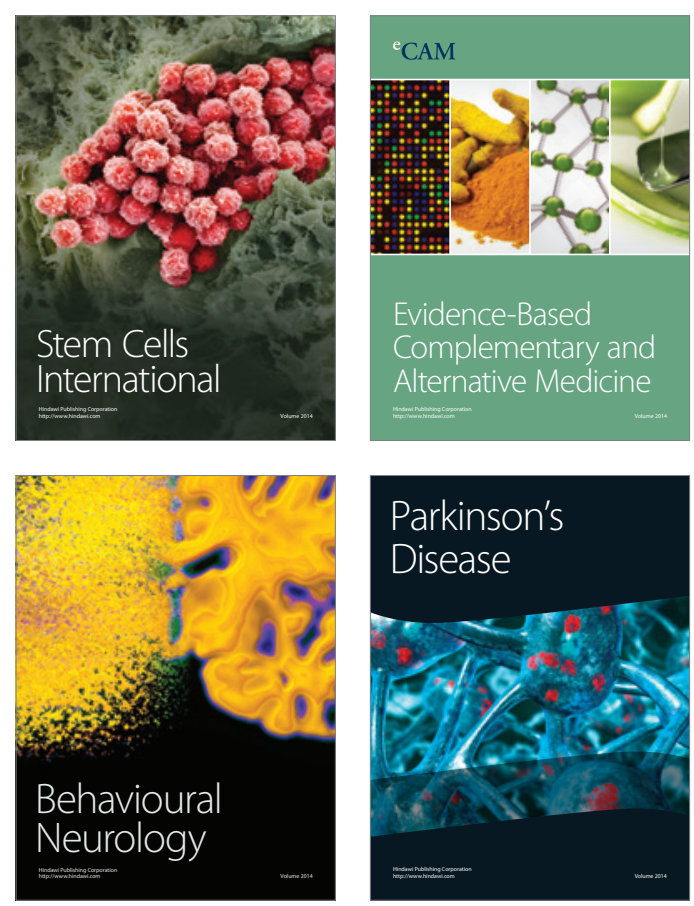

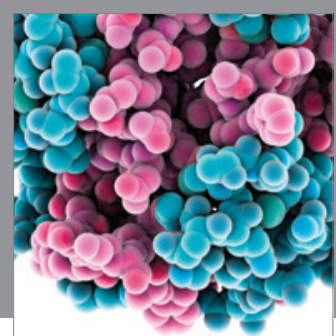

Journal of
Diabetes Research

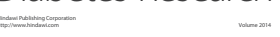

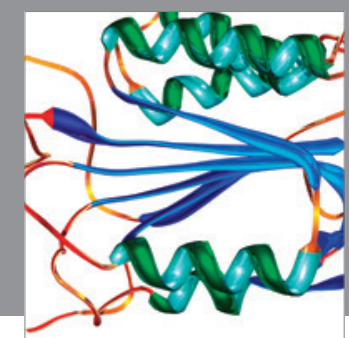

Disease Markers
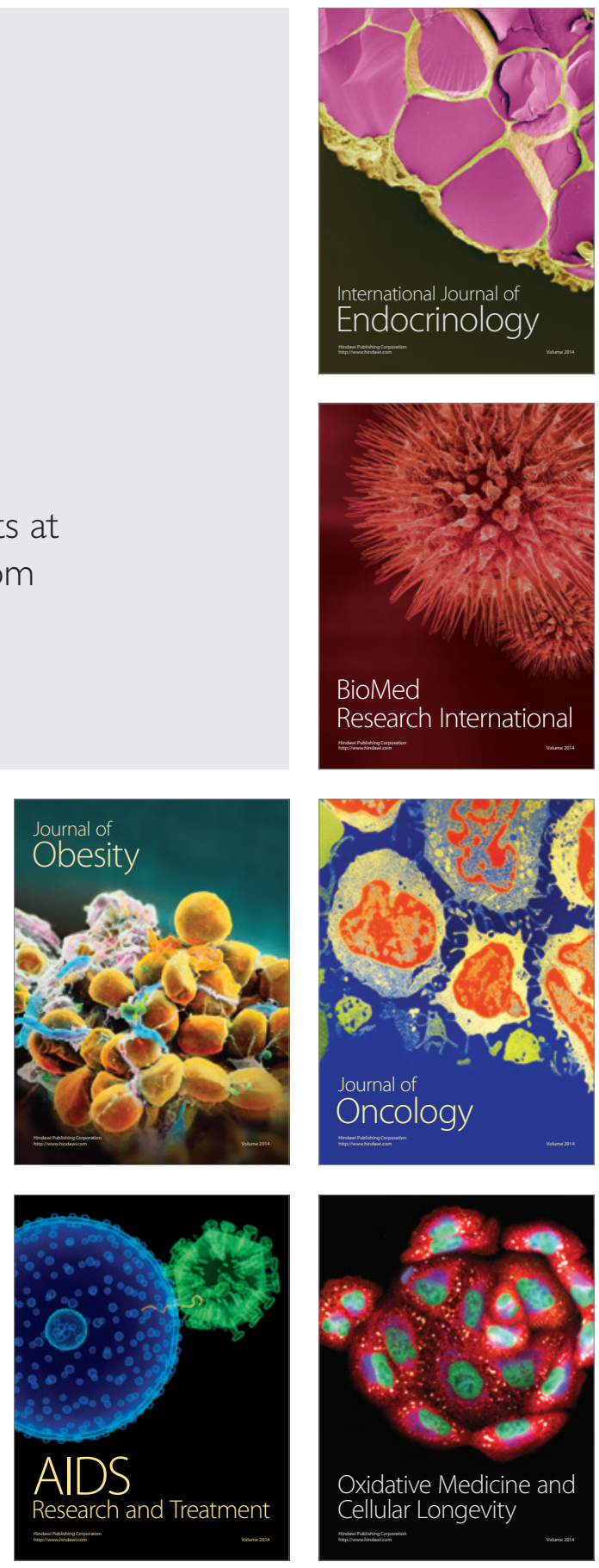